Article

\title{
Optimizing TEG Dehydration Process under Metamodel Uncertainty
}

\author{
Rajib Mukherjee ${ }^{1,2}$ and Urmila M. Diwekar ${ }^{2, *}$ \\ 1 Department of Chemical Engineering, The University of Texas Permian Basin, Odessa, TX 79762, USA; \\ mukherjee_r@utpb.edu \\ 2 Vishwamitra Research Institute, Crystal Lake, IL 60012, USA \\ * Correspondence: urmila@vri-custom.com; Tel.: +1-630-886-3047
}

Citation: Mukherjee, R.; Diwekar, U.M. Optimizing TEG Dehydration Process under Metamodel Uncertainty. Energies 2021, 14, 6177. https://doi.org/10.3390/ en14196177

Academic Editor: Claudio Mele

Received: 29 July 2021

Accepted: 23 September 2021

Published: 28 September 2021

Publisher's Note: MDPI stays neutral with regard to jurisdictional claims in published maps and institutional affiliations.

Copyright: (c) 2021 by the authors. Licensee MDPI, Basel, Switzerland. This article is an open access article distributed under the terms and conditions of the Creative Commons Attribution (CC BY) license (https:// creativecommons.org/licenses/by/ $4.0 /)$.
Abstract: Natural gas processing requires the removal of acidic gases and dehydration using absorption, mainly conducted in tri-ethylene glycol (TEG). The dehydration process is accompanied by the emission of volatile organic compounds, including BTEX. In our previous work, multi-objective optimization was undertaken to determine the optimal operating conditions in terms of the process parameters that can mitigate BTEX emission using data-driven metamodeling and metaheuristic optimization. Data obtained from a process simulation conducted using the ProMax ${ }^{\circledR}$ process simulator were used to develop a metamodel with machine learning techniques to reduce the computational time of the iterations in a robust process simulation. The metamodels were created using limited samples and some underlying phenomena must therefore be excluded. This introduces the so-called metamodeling uncertainty. Thus, the performance of the resulting optimized process variables may be compromised by the lack of adequately accounting for the uncertainty introduced by the metamodel. In the present work, the bias of the metamodel uncertainty was addressed for parameter optimization. An algorithmic framework was developed for parameter optimization, given these uncertainties. In this framework, metamodel uncertainties are quantified using real model data to generate distribution functions. We then use the novel Better Optimization of Nonlinear Uncertain Systems (BONUS) algorithm to solve the problem. BTEX mitigation is used as the objective of the optimization. Our algorithm allows the determination of the optimal process condition for BTEX emission mitigation from the TEG dehydration process under metamodel uncertainty. The BONUS algorithm determines optimal process conditions compared to those from the metaheuristic method, resulting in BTEX emission mitigation up to 405.25 ton/yr.

Keywords: TEG dehydration process; BTEX mitigation; metamodeling uncertainty; support vector regression (SVR); BONUS algorithm; Value of Stochastic Solution (VSS)

\section{Introduction}

Natural gas (NG) obtained from oil and gas wells needs to be sweetened, followed by dehydration for preprocessing to meet sales gas requirements. Dehydration is mainly performed by absorption in tri-ethylene glycol (TEG). The process consists of an absorption column, a flash tank, a stripping column, and a reboiler. The wet gas from the NG sweetening process contains, in addition to water, different volatile organic compounds (VOCs), such as toluene, benzene, ethylbenzene, and isomers of xylene, known as BTEX, and is transported to the absorption column where it comes into contact with lean TEG. Rich TEG with water and BTEX flows through a flash tank from the absorption column to the regeneration column. The total BTEX and other VOC emissions from the dehydration process originate from the flash tank and regeneration unit. In our previous work, metamodels were developed from the simulated process data and metaheuristic optimization to optimize different process variables for BTEX emission reduction and maintain the dry gas specification [1]. The uncertainty involved in the optimization process is either 
related to data, including inlet feed composition, flow rate, or metamodeling [2]. The metamodel-based design of the system treated the metamodel as the real model, ignoring the influence of metamodeling uncertainty. Thus, the resulting optimized process variables may be compromised by the lack of adequately accounting for the uncertainty introduced by the metamodel. In the present work, the bias of metamodel uncertainty was addressed for process variable optimization. An algorithmic framework was developed to address the problem of process variable optimization under metamodel uncertainties. In this framework, we use the novel Better Optimization of Nonlinear Uncertain Systems (BONUS) algorithm to solve the problem $[3,4]$. The objective of the optimization process is to mitigate BTEX emission with dry gas water content as a constraint. The effectiveness of our algorithm is shown by the increased value of the stochastic solution (VSS) at lower dry gas water content.

Aromatics are often present in natural gas in trace amounts. Research findings of the CDC revealed severe health impacts of BTEX [5]. BTEX compounds are toxic in nature, and can produce neurological complications and carcinogenic effects. During the dehydration process, water and BTEX are absorbed in glycol in the absorption unit, which is later released to the atmosphere from the regenerator. Thus, sustainable natural gas processing requires the mitigation of BTEX emissions. The US Clean Air Act Amendments (CAAA) from 1990 regulates BTEX emissions of more than ten tons per year for any given facility, or more than twenty-five tons per year for the total hazardous air pollutants (HAP). Accordingly, several dehydration plants are classified as major BTEX polluters [6,7]. TEG has the highest BTEX affinity among different glycol dehydrates, which results in maximum emissions from the process.

The existing literature on optimizing the natural gas dehydration process primarily comprises sensitivity analysis for determining the influence of different process parameters. Gupta et al. [8] carried out a sensitivity analysis to obtain process conditions that can optimally reduce loss of TEG. A parametric study was performed by Gandhidasan [9] to determine the effect of parameters such as pressure, temperature, and TEG circulation rate on the design of the dehydration unit. Rahimpour et al. [10] improved the dehydration unit's performance using process simulations. Jacob [11] found that the stripping gas flow rate has a larger impact on drying than the reboiler temperature by studying the effect of the number of plates in the absorber and TEG circulation rates on dry gas water. Ranjbar et al. [12] used relative sensitivity analysis to optimize the TEG plants. HYSYS ${ }^{\circledR}$ process simulator data was used for their analysis. Kamin et al. [13] used Design Expert software and the HYSYS ${ }^{\circledR}$ simulator for data generation and subsequent optimization of the glycol circulation rate, reboiler temperature, and the number of trays in the absorber. Neagu and Cursaru [14] considered the effect of the reboiler temperature and stripping gas flow rate, and found that the optimum stripping gas flow rate can enhance TEG regeneration and reduce dry gas water content. Chebbi et al. [15] optimized both the process and design parameters. TEG concentration and circulation rate, and the number of trays in the absorber, were optimized to minimize the capital cost, TEG pumping, utility requirements for the reboiler, and stripping gas rate. Mukherjee and Diwekar [1] performed a multi-objective optimization (MOO) of the dehydration process with economic and environmental objectives using a metamodel of the process. Traditionally, sustainable process design estimates design parameters based on economic, environmental, and societal aspects, using process sustainability assessment tools in a retroactive manner [16,17]. Traditionally, greenhouse gas (GHG) emissions are considered for environmental impact assessment $[18,19]$. Mukherjee and Diwekar [1] addressed environmental sustainability through BTEX mitigation with process parameter optimization. Process data was generated using the ProMax ${ }^{\circledR}$ simulator, which was used to derive the surrogate model for optimization. However, the surrogate model considered was subjected to metamodeling uncertainty, which arises due to the error between the process model and the metamodel at unsampled locations [20]. Metamodeling uncertainty is often overlooked in model-based optimization. To address the MOO problem under metamodeling uncertainties, this study developed a new framework called MOO 
under metamodeling uncertainties (MOOMU). The selected process data are employed to construct the support vector regression (SVR) metamodels of the objective and constraint. Hammersley sequence sampling (HSS) of the error distributions is adopted to quantify the impact of metamodeling uncertainties. The MOOMU framework is employed to explore the optimum TEG dehydration process.

Essential variables differ among chemical systems due to the difference in their type, scale, and properties. In cases in which many variables are present, important variable selection is required; variables can be selected using multivariate statistics or machine learning [21-23]. In the present problem, important variables selected through lasso, as found in Mukherjee and Diwekar (2021), were used [1]. Surrogate models are generated to quantify the effects of the important variables on the corresponding dependent variables of the process. In the present work, support vector regression (SVR), which is a machine learning technique, was applied for metamodel generation. The SVR-based metamodel thus developed is used for the optimization of the process with the BONUS algorithm. Through optimization, the optimal process operating variables that minimize BTEX/VOC emissions at the different dry gas water content limits were determined.

Metamodel uncertainty arises due to the dispersed nature of the input-output data used for developing the model. In this work, optimization of the input space of the SVR metamodel was performed with a stochastic optimization known as Better Optimization for Nonlinear Uncertain Systems (BONUS). The BONUS algorithm uses a reweighting scheme to obtain the value of the stochastic objective function and constraints and derivatives. In our previous work, the metamodel generated from the simulated data was used for optimization without considering its uncertainty. In this work, we quantify the uncertainties as error function distributions. The objective function and constraints were changed from deterministic values to expected values. Previously, BONUS has been extensively used to solve chemical engineering problems, including network optimization [24] and spatiotemporal sensor placement $[25,26]$. In the present work, we developed an algorithmic framework for a robust metamodel-based chemical process optimization that significantly reduces the impact of metamodel uncertainty using BONUS.

This paper is organized as follows. The next section describes the dehydration process in natural gas processing and emissions from the process. The solution methodology section explains process simulation for data generation, modeling using SVR, and multiobjective optimization using BONUS. This is followed by presentation of the results from the application of the SVR-BONUS-based algorithm for dehydration process optimization and the effect on different process variables, followed by conclusions.

\section{Materials and Methods}

\subsection{Problem Description}

Natural gas processing comprises two process units: acid gas removal and dehydration. Dehydration can be performed by different methods, including via the use of liquid hygroscopic substances such as glycols, solid hygroscopic substances, and condensation. Glycol as a dehydrating agent has several advantages, including dehydration capacity, VOC absorption, and loss. TEG is the most-used glycol in industrial applications and is the subject of our analysis. TEG dehydration process has an absorption section and a stripping section. Lean TEG entering the tower in the absorption section absorbs water from wet gas. Rich TEG solvent leaving the absorber is regenerated by a stripper moister in a regenerator. Stripping gas is injected into the reboiler by drawing from the dry gas stream. The regenerated TEG is sent back to the absorber for desiccation. A schematic diagram of the TEG dehydration process is shown in Figure 1. 


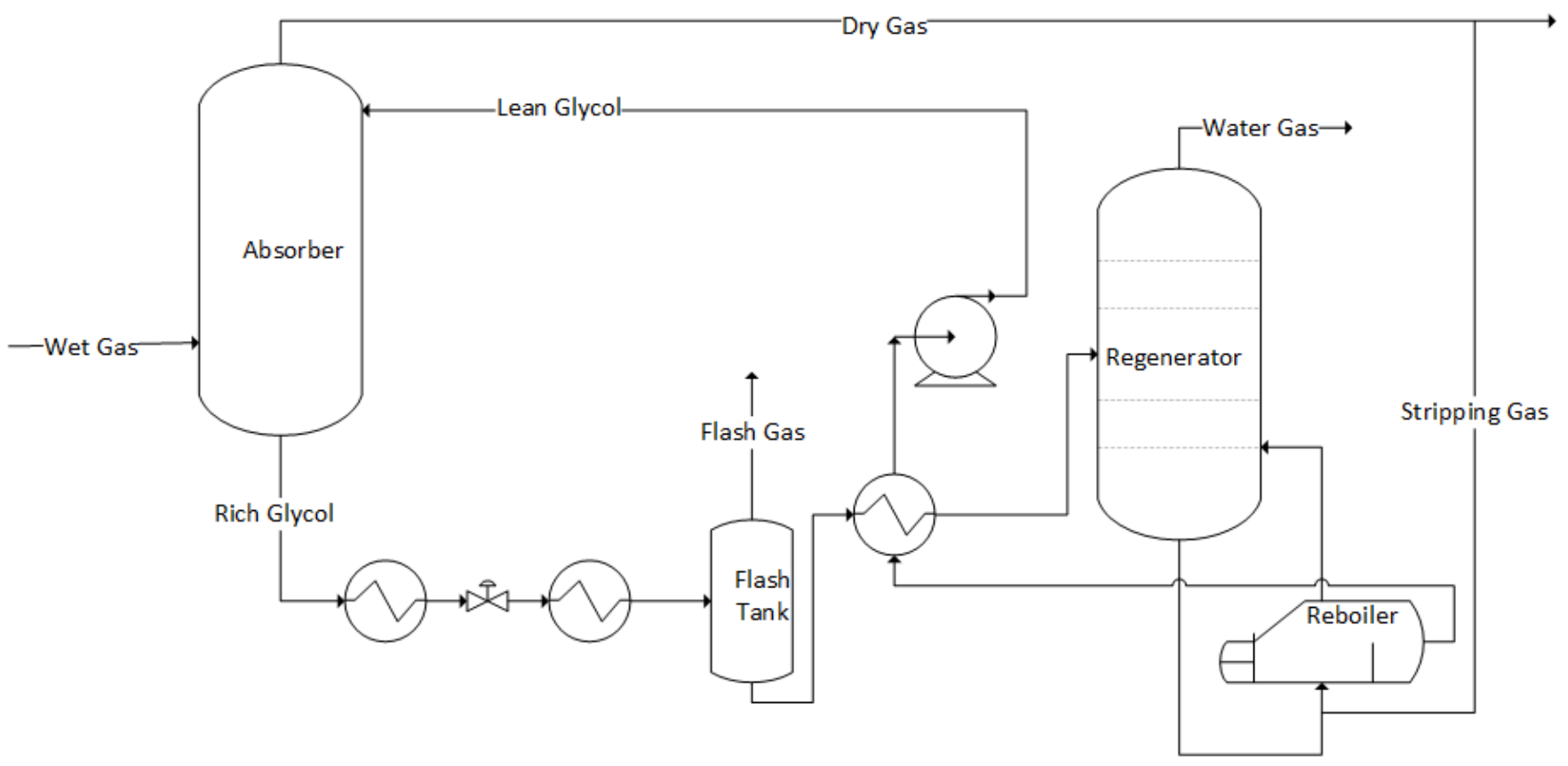

Figure 1. Schematic diagram of the NG gas dehydration process.

The flash tank and the stripping column release water vapor and aromatics absorbed in the absorber into the atmosphere. BTEX/VOC mitigation can be achieved by incineration, flaring, or condensation; these approaches are not environmentally friendly. Incineration or flaring can cause air pollution. Condensation results in BTEX/VOC pollution of water. Break et al. [27] optimized the process parameters and significantly reduced BTEX/VOC generation. Their study found that the glycol circulation rate and stripping gas rate are important parameters that impact BTEX/VOC emission. In addition to these two process variables, reboiler temperature and flash tank pressure also impact BTEX and VOC emission.

The process variables that affect BTEX/VOC emission also influence the dew point of the dry gas. Thus, we have a multi-objective optimization problem where the system must fulfill the emission goal and meet the water dew point requirements. Traditionally, the developed metamodel is used for optimization. Different optimization methods can be used for data-driven model generation and optimization of the process variables. The optimization process assumes the data-driven model is a true representation of the process, ignoring metamodel uncertainty. In the present work, Better Optimization for Nonlinear Uncertain Systems (BONUS) was used for optimization [4]. Finally, the optimal solution was found from the Pareto front generated using multi-objective optimization.

\subsection{Solution Methodology}

The framework for process simulation and optimization with BONUS is shown in Figure 2. Here MATLAB ${ }^{\circledR}$ is used as a controller, and the FORTRAN module is used for multi-objective optimization (MOO) and ProMax ${ }^{\circledR}$ is used for process simulation. Input variables are generated by MATLAB ${ }^{\circledR}$. These are selected from a uniform distribution using Halton sequence-based quasi-random sampling. The uniformity property is important in sampling [28]. The Halton sequence has high dimensional uniformity [29]. The performance of the metamodel increases manifold through this efficient sampling technique [30]. The metamodel is generated with the output responses from the process simulation data. The uncertainty associated with metamodeling is quantified by the probability distribution of errors found from the difference with the process simulated outputs. The optimization is performed by propagating the uncertainty through the metamodel to identify the optimal parameters to mitigate BTEX emissions. 


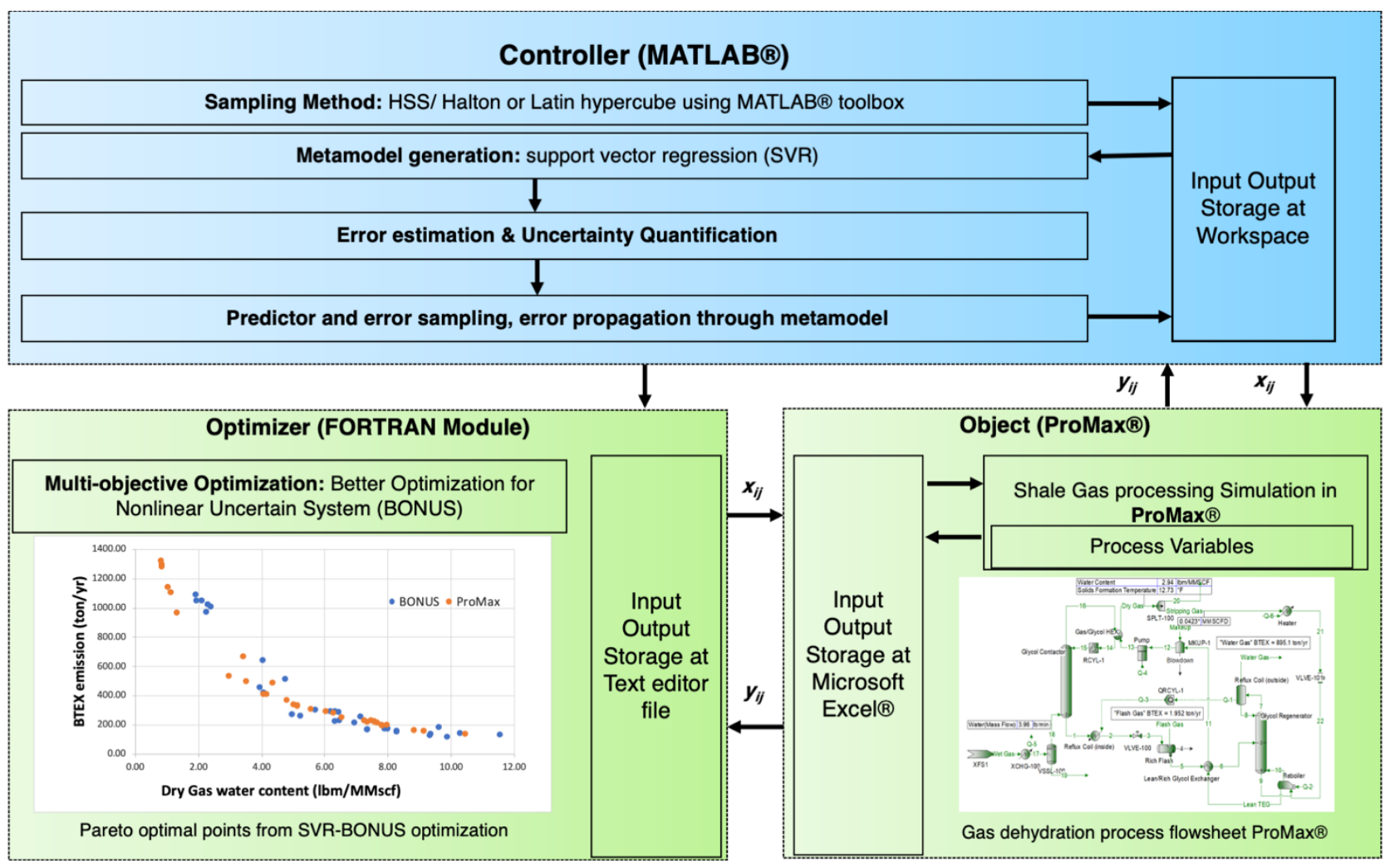

Figure 2. Framework for the simulation, data-based modeling, uncertainty quantification, error propagation, and optimization of the natural gas dehydration process.

The steps in the natural gas process response generation and optimization for BTEX mitigation are as follows:

1. Identification of the decision variables of the natural gas (NG) processing system and defining them (with their range).

2. Input sample space generation using the Halton sequence in MATLAB ${ }^{\circledR}$.

3. NG process response generation using the ProMax ${ }^{\circledR}$ model.

4. SVR-based metamodel generation for the objective and constraints using MATLAB ${ }^{\circledR}$.

5. Error estimation and uncertainty quantification using kernel density estimator (KDE) in MATLAB ${ }^{\circledR}$.

6. Predictor and error space sampling and error propagation through the metamodels in MATLAB ${ }^{\circledR}$.

7. Stochastic multi-objective optimization under specified constraints and bounds for the Pareto optimal solution using a FORTRAN inhouse module.

\subsubsection{Acid Gas Removal Unit Process Simulation}

Natural gas processing comprises acid gas removal unit and a dehydration unit, as shown in Figure 3. The acid gas removal unit removes carbon dioxide and hydrogen sulfide. Water is removed in the dehydration unit. In this work, ProMax ${ }^{\circledR}$ software is used to simulate acid gas removal and dehydration units. Detailed descriptions of the dehydration unit for which optimal conditions were studied are presented. Results from the ProMax ${ }^{\circledR}$ simulator are presented in the supporting document. 


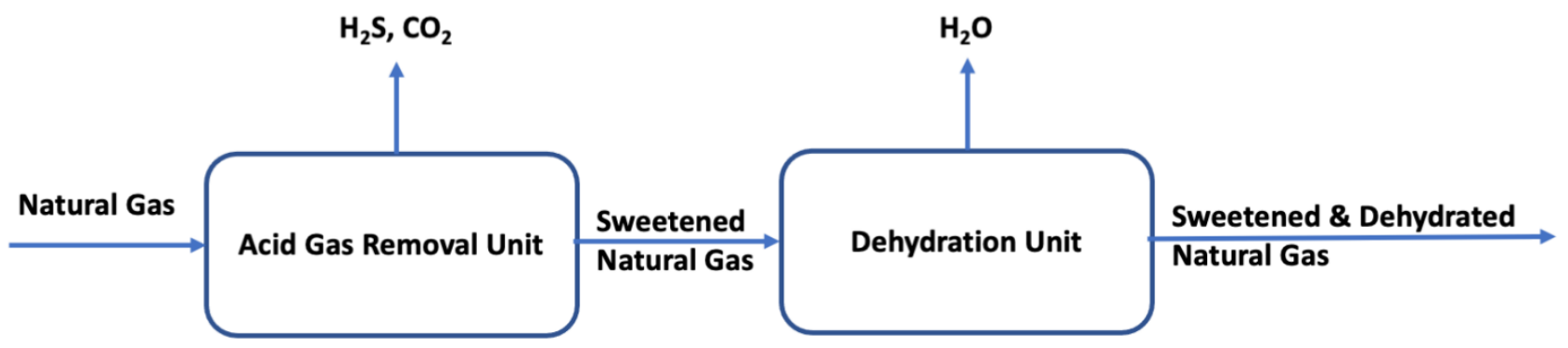

Figure 3. Block flow diagram of natural gas processing.

In this work, acid gas removal is performed with the amine absorption process. Methyl di-ethanol amine (MDEA) is used as an absorbent. Sweet gas from the acid gas removal unit is dehydrated to meet the pipeline specification of 4 to $7 \mathrm{lbm} / \mathrm{MMscf}$ [31]. As mentioned previously, tri-ethylene glycol (TEG) absorption is selected as an absorbent for dehydration. Figure 4 shows the ProMax ${ }^{\circledR}$ process flow diagram of the TEG dehydration process. Process conditions are from the ProMax ${ }^{\circledR}$ reference example model Ex05-TEG Dehydration [32]. Details of the process condition can be found in Mukherjee and Diwekar, 2021 [1]. In the present work, sampling from a uniform distribution of the decision variables' range is performed, and the resulting impact on emission and drying is observed. Our analysis considers the total BTEX emission from the Water Gas stream from the stripping section and the Flash Gas stream from the flash tank.

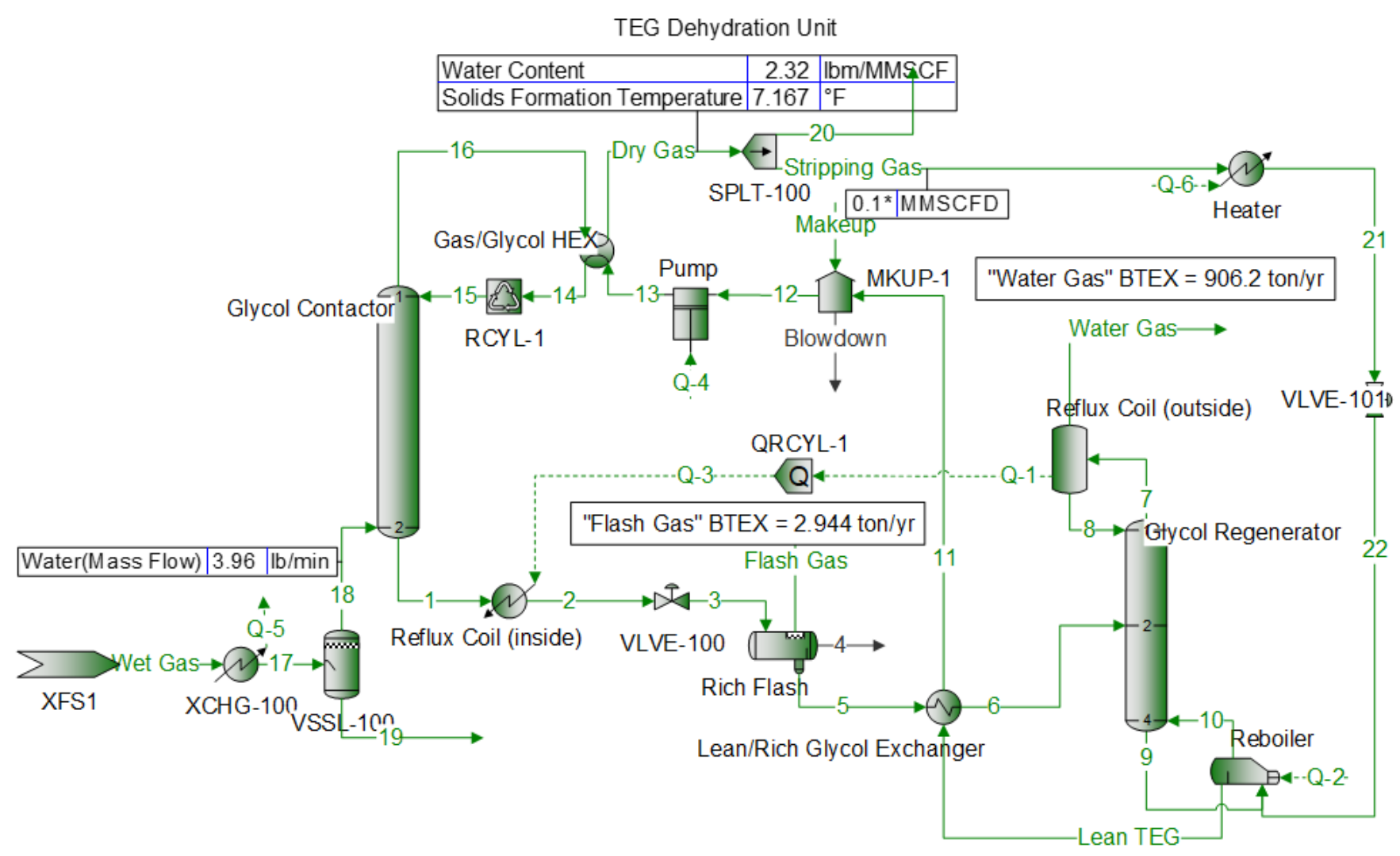

Figure 4. Process flowsheet for the NG dehydration in ProMax ${ }^{\circledR}$. Here the Stripping Gas is obtained from the Dry Gas stream. 


\subsubsection{Data Generation and Process Optimization}

The present work aims to determine the optimal operating conditions in a glycol dehydration unit that will minimize BTEX emission and fulfill the dew point requirement using an efficient data-driven optimization method. In most TEG dehydration plants, the glycol circulation is more glycol than the minimum required. Thus, it is imperative to optimize circulation. The other process variables, including stripping gas flow rate, reboiler temperature, absorber pressure, flash gas pressure, and lean solvent temperature, may also impact BTEX/VOC emission. In this work, as identified by Mukherjee and Diwekar (2021), the process variables that have a significant impact on BTEX emission are used [1].

For a natural gas dehydration unit, two different goals need to be achieved. The process should have a high drying efficiency and be environmentally friendly with minimum toxic release, resulting in a multi-objective optimization (MOO) problem. The solution of $\mathrm{MOO}$ is typically achieved by quantifying the trade-offs between the two conflicting objectives. The economic objective, drying efficiency, and the environmental objective, BTEX mitigation, are conflicting in nature. Thus, the impact of the different process variables can show completely different trends. MOO is solved by either preference-based methods or generating methods [33]. The weighting and constraint method, as used in the present work, is a generating method. Here we can generate a set of solutions known as the Pareto set. The Pareto set provides the trade-off surface between the conflicting objectives. Our goal is to minimize the emission within the dry gas water content specifications, which is between 4 and $7 \mathrm{lbm} / \mathrm{MMscf}$ [31]. The $\varepsilon$ - constraint method that shows the Pareto points is used.

The process optimization objective in the present problem needs to find the optimal values of the process variables where the BTEX emission $\left(y_{B T E X}\right)$. is minimized while maximizing drying, i.e., minimizing dry gas water content $\left(y_{D r y W}\right)$. The constraint optimization method is formulated as:

$$
\begin{gathered}
\text { minimize } y_{B T E X}=f_{B T E X}\left(x, w_{f_{B T E X}}\right) \\
\text { Subject to } y_{D r y W} \equiv f_{D r y W}\left(x, w_{f_{D r y W}}\right) \leq \varepsilon_{D r y W} \\
h_{I}(x)=0 I \geq 0 \\
g_{J}(x) \leq 0 J \geq 0 \\
l_{i} \leq x_{i} \leq u_{i} i=1,2, \ldots . n .
\end{gathered}
$$

where the objective functions $y_{B T E X}$ and $y_{D r y W}$ denote BTEX emission and dry gas water content respectively, $x=\left[x_{1}, x_{2}, \ldots, x_{n}\right]^{T}$ is the $n$-dimensional vector of process operating variables, $f_{B T E X}$ is the function correlating BTEX emission and $f_{D r y W}$ is that correlating dry gas water content with the inputs estimated with machine learning, and $w_{f_{B T E X}}$ and $w_{f_{\text {DryW }}}$ are the parameter vector of the functions $f_{B T E X}$ and $f_{\text {DryW }}$ respectively; $h$ and $g$ are equality and inequality constraints, respectively, and $u_{i}$ and $l_{i}$ are the upper and the lower bound of $x_{i}$, respectively. Equations (1)-(5) describe an $\varepsilon$-constrained method.

The optimization problem is solved multiple times by changing the value of the parameter on the right-hand side as in Equation (2) to generate the Pareto set. The optimization is performed in two steps. Firstly, the support vector regression-based process models, $f_{B T E X}\left(x, w_{f_{B T E X}}\right)$ and $f_{D r y W}\left(x, w_{f_{\text {Dry }}}\right)$, is developed, followed by error analysis with estimation, uncertainty quantification, variable sampling error propagation, and finally optimizing the input space $(x)$ of the process using BONUS to minimize the objective function as given in Equation (1).

\subsubsection{Metamodel Generation with Support Vector Regression (SVR)}

Metamodeling of complex chemical process phenomena has been used in multiple applications [34]. Traditionally, metamodels are statistical or polynomial in nature. The 
metamodel adopted in this work is based on support vector machines (SVMs), known as support vector regression (SVR). SVM is a statistical learning algorithm [35,36]. A function relating the input variables and the response of the entire natural gas processing system was created using SVR. Generally, metamodel-based optimization of a process using either gradient-based methods or metaheuristic techniques will assume that there is no error associated with the model. Due to limited real plant or simulated data, the metamodel thus developed is subject to an error, leading to a suboptimal solution. In this work, we used a rigorous error analysis method to overcome the uncertainty associated with metamodel uncertainty.

\subsubsection{Uncertainty Quantification}

The data-driven metamodel of a chemical process often uses a small number of actual plant or simulated data to construct the models. However, due to the limited data, the metamodel is developed on a particular region of the entire design space, and errors are associated with the model. For the present problem, the BONUS optimization algorithm adopted uncertainty associated with the model for optimization. In the first step, the objectives obtained from the ProMax ${ }^{\circledR}$ process simulation (because we are considering ProMax simulation as the actual plant simulation here) are compared with those from the SVR metamodel for error estimation. For example, the percentage error associated with BTEX emission ( err $\left._{B T E X}\right)$ and with the error in dry gas moisture content (error $\left.{ }_{D r y W}\right)$ is:

$$
\begin{gathered}
\operatorname{err}_{\text {BTEX }}=\left|\frac{Y_{\text {BTEX }}^{\text {process simulation }}-f_{\text {BTEX }}\left(\boldsymbol{x}, \boldsymbol{w}_{f_{\text {BTEX }}}\right)}{f_{\text {BTEX }}\left(x, w_{f_{B T E X}}\right)}\right| \times 100 \\
\operatorname{err}_{\text {DryW }}=\left|\frac{Y_{\text {DryW }}^{\text {process simulation }}-f_{\text {DryW }}\left(\boldsymbol{x}, \boldsymbol{w}_{f_{\text {Dry }}}\right)}{f_{\text {DryW }}\left(x, w_{f_{\text {Dry }}}\right)}\right| \times 100
\end{gathered}
$$

The uncertainty associated with the metamodel is then quantified with probability using kernel density estimation (KDE). Similarly, error estimation is also undertaken for dry gas water content $\operatorname{err}_{\operatorname{DryG}}$ and the uncertainty is quantified with kernel density estimation. These uncertainties are presented as distributions in Figure 5. Thus, we can ascertain the process performance at corresponding process variable set points considering uncertainty. Details of the metamodel generation using SVR are described in Mukherjee and Diwekar, $2021[1]$.

\subsubsection{Stochastic Optimization Using BONUS}

The uncertainty associated with the metamodel has converted the problem into stochastic optimization, as given below.

$$
\begin{gathered}
\text { minimize } y_{\text {BTEX }}=E\left(f_{B T E X}\left(\boldsymbol{x}, \boldsymbol{w}_{f_{\text {BTEX }}}\right)\right) \\
\text { subject to } y_{\text {DryW }} \equiv E\left(f_{\text {DryW }}\left(\boldsymbol{x}, \boldsymbol{w}_{f_{\text {Dry }}}\right)\right) \leq \varepsilon_{\text {DryW }} \\
E\left(h_{I}(x)\right)=0 I \geq 0 \\
E\left(g_{J}(x)\right) \leq 0 J \geq 0
\end{gathered}
$$

where $E$ is the expected value. The objective function and the constraint are probabilistic in nature. A generalized approach involves capturing uncertainty through a sampling loop that is embedded within the optimization iterations that decide the decision variables, as shown in Figure 6. 


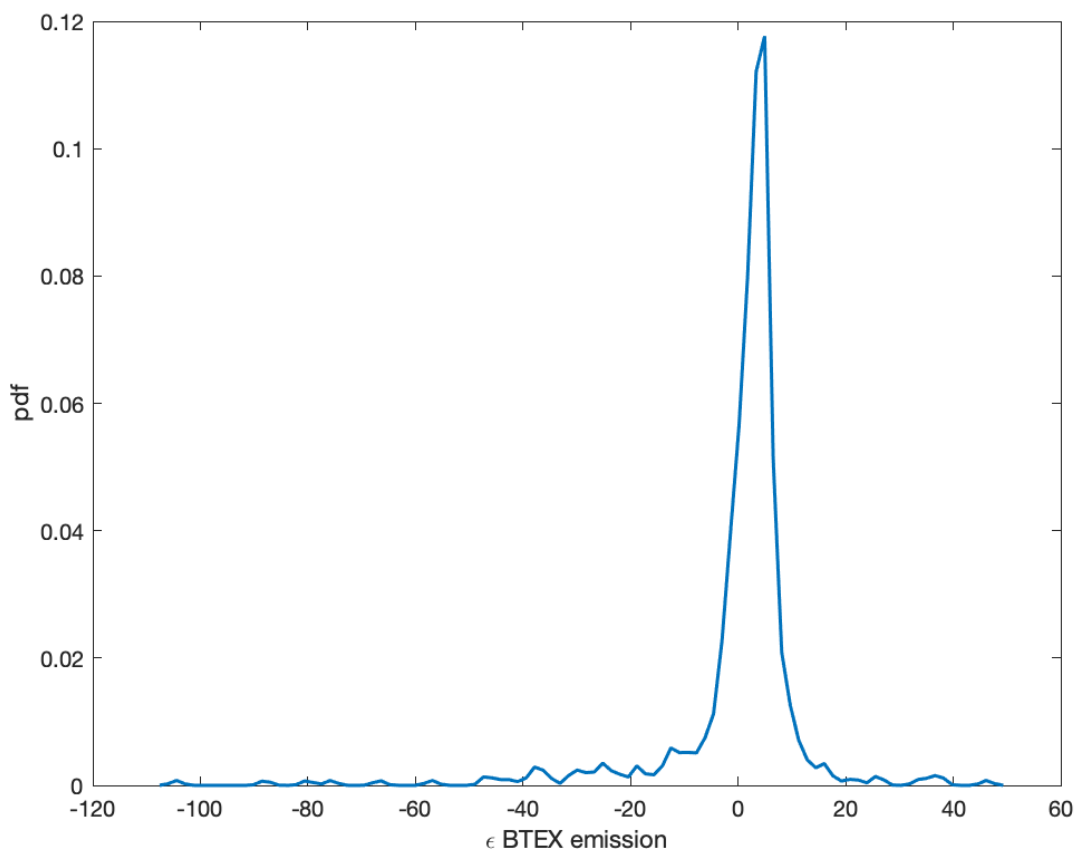

(a)

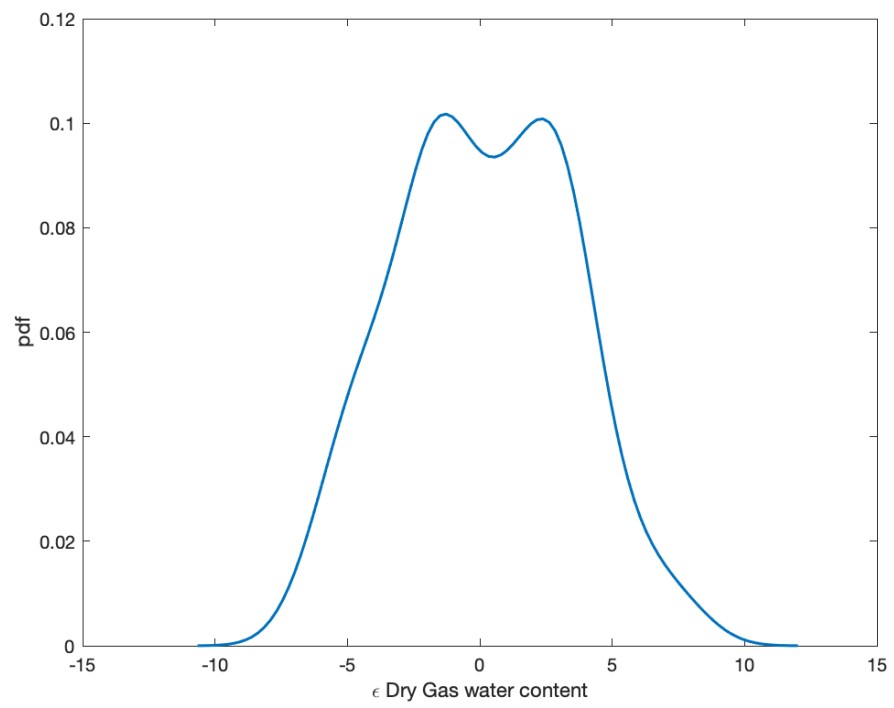

Figure 5. Percentage error $\mathrm{err}_{i}$ distribution as obtained from metamodel predicting: (a) BTEX emission, (b) dry gas water content. 


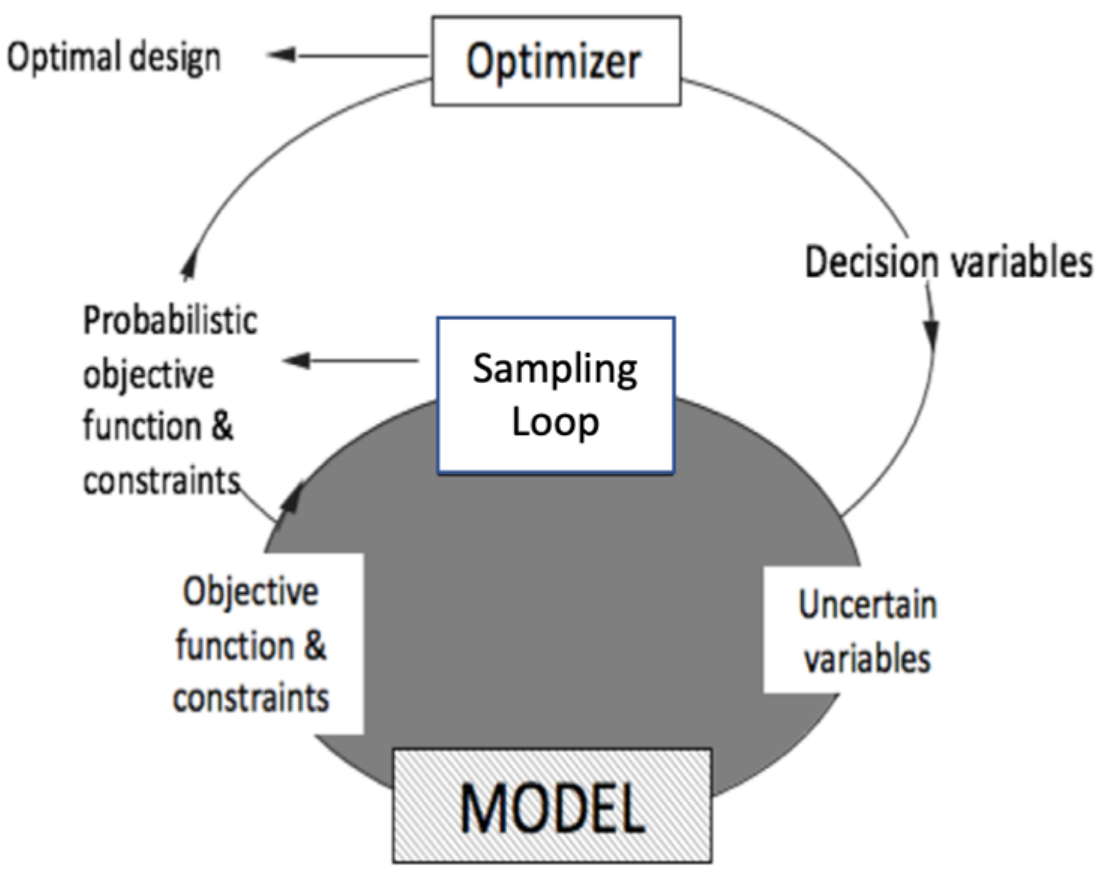

Figure 6. Generalized calculation procedure for a stochastic optimization problem.

Here, the outer optimization loop finds the values of the decision variables, and the inner loop obtains a probabilistic representation of the objective function and constraints using the sampling loop or scenario loop. For each iteration, the decision variables selected by the optimization loop are used in the inner loop where a sample set or scenario set of uncertain variables is generated, and the model is run for each of these sample (scenario) points to obtain probabilistic objective and constraint values. The derivative information is also needed for nonlinear programming problems, which involves perturbation of each decision variable, and also to perform the sampling. The computational burden of this method is heavy. The Better Optimization of Nonlinear Uncertain Systems (BONUS) algorithm was proposed by Sahin and Diwekar (2004) [3] to avoid this problem.

BONUS requires the sampling loop to be run only for the first iteration (Figure 6). In this first iteration, the decision variables (the four variables in our problem) are assumed to have uniform distributions between upper and lower bounds. Specified probability distributions of uncertain variables (the error distribution of the two predicted variables), together with the uniform distribution of the decision variables, form the base distributions for analysis and are used in the first iteration. As the optimization proceeds, the decision variables change, and the underlying distributions for the objective function and constraints also change. Here, instead of again using the sampling loop, a reweighting scheme based on the ratios of the probabilities for the current and the base distributions is used to determine the values of the objective function and constraints for that iteration. Please refer to Figure 7 for the reweighting approach. To ensure a smooth function for the probabilities, we approximate the distributions using kernel density estimation techniques. Please refer to Diwekar and David (2015) [4]. 


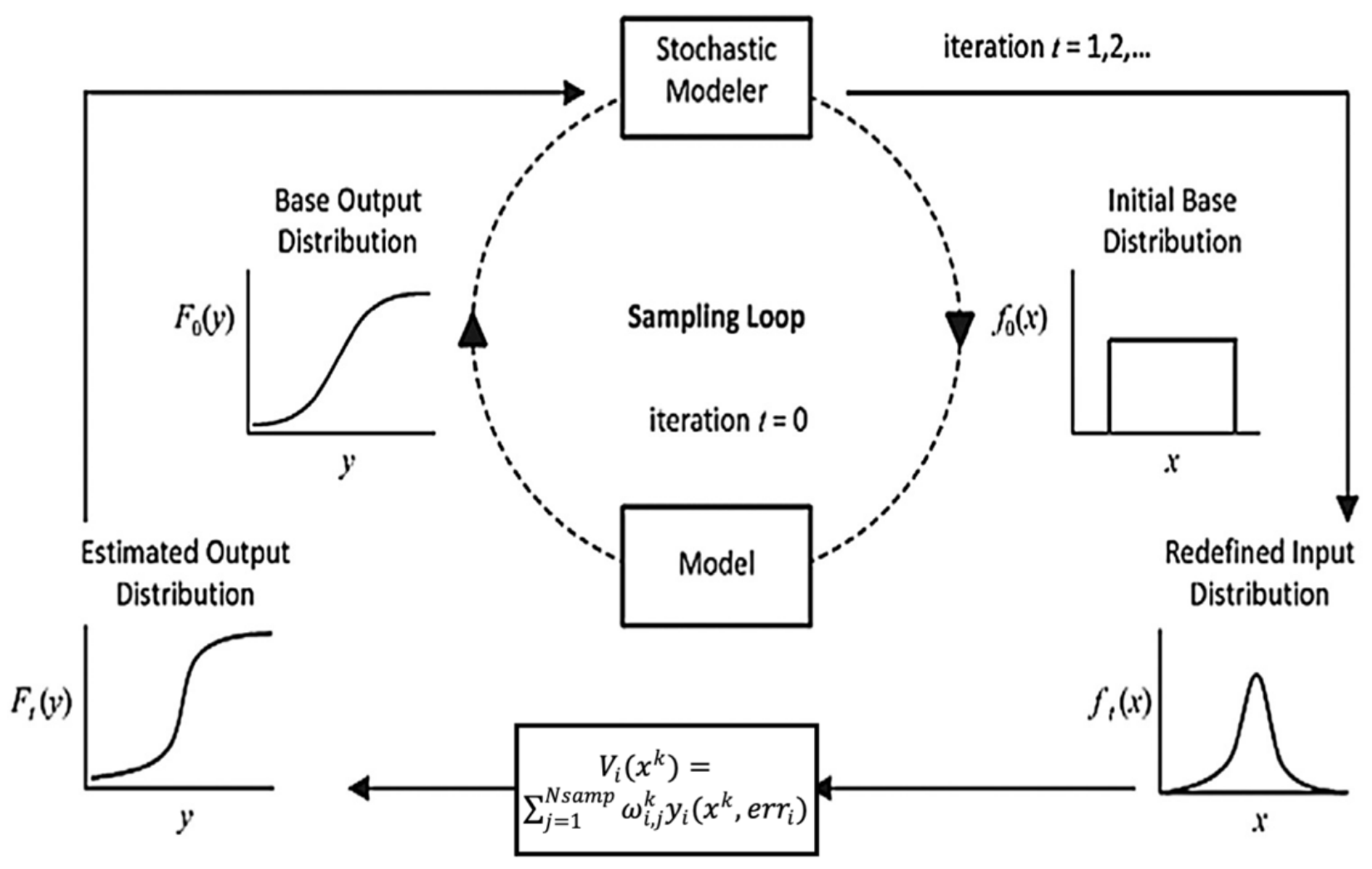

Figure 7. BONUS reweighting approach.

We used the Hammersley sequence sampling (HSS) for the initial base distributions in this problem. The BONUS algorithm is a sequential quadratic programming (SQP) algorithm that uses the reweighting scheme to estimate the objective function and gradient at each iteration instead of the sampling loop. The Hessian is approximated using the Broyden-Fletcher-Goldfarb-Shanno (BFGS) formula. The objective of the BONUS optimization is to find the $n$-dimensional optimal decision variable vector, $x^{*}=\left[x_{1}^{*}, x_{2}^{*}, \ldots, x_{n}^{*}\right]^{T}$ that represents the optimal process conditions where the process output, $E\left(y_{B T E X}\right)$, is minimized while fulfilling the constraint $E\left(y_{D r y W} \leq \varepsilon\right.$. The general procedure involved is described below.

1. Off-line Computations (generating base distributions and objective function data from metamodel): Obtain independently distributed samples $j=1$, Nsamp for metamodel uncertainty $\operatorname{err}_{i}$ (where $i$ represents BTEX for BTEX emission or DryG for dry gas water content) and decision variables $x$ with uniform distribution between upper and lower bounds. These samples are used to generate the design prior density function $P^{p}\left(x, e^{r r} r_{i}\right)$ using kernel density estimation (KDE). Calculate the objective function $y_{i}$ (and the probabilistic constraint) for each sample. For example, the sampled error $\operatorname{err}_{B T E X}$ is used to generate objective function $y_{B T E X}$ for estimated BTEX emission as:

$$
y_{B T E X}=f_{B T E X}\left(x, w_{f_{B T E X}}\right) \times\left(1+\frac{\operatorname{err}_{B T E X}}{100}\right)
$$

Similar estimation is also undertaken for dry gas water content $y_{D r y G}$.

2. On-line Computations (using BONUS reweighting scheme to solve the BTEX minimization problem):

a. At each iteration $k$, the decision variables $x^{k}$ (in the first iteration, the initial value of decision variables is given), define a narrow normal distribution around this point (see Figure 6) and draw samples of $x^{k}$ from it. Use samples to generate the 
design distribution $P^{d}\left(x, e r r_{i}\right)$ using KDE. Estimate the objective functions and constraint (expected value $E$ ) using the following reweighting formula:

$$
V_{i}\left(x^{k}\right)=E\left(y_{i}\left(x, \operatorname{err}_{i}\right)\right)=\sum_{j=1}^{N s a m p} \omega_{i, j}^{k} y_{i}\left(x^{k}, \operatorname{err}_{i}\right)
$$

where

$$
\omega_{i, j}^{k}=\frac{P^{d}\left(x_{j}^{k}\right) e r r_{i} / P^{p}\left(x_{j}^{k}\right) \operatorname{err}_{i}}{\sum_{j j=1}^{N s a m p} P^{d}\left(x_{j j}^{k}\right) e r r_{i} / P^{p}\left(x_{j j}^{k}\right) e r r_{i}}
$$

and sastisfy

$$
\sum_{j=1}^{\text {Nsamp }} \omega_{i, j}^{k}=1
$$

b. Perturb the decision variable $x^{k}$ and use the reweighting scheme to estimate $V_{i}\left(x^{k}+\delta x^{k}\right)$. Find the gradient and KKT conditions. If KKT conditions are satisfied, terminate, go to step 2.c.

c. SQP computation: Use the gradient to compute the Hessian approximation $H_{i}{ }^{\mathrm{k}}$ using the BFGS formula and compute step $\Delta x$ for decision variables by solving the quadratic program $(\mathrm{QP})$ :

$$
\begin{gathered}
\min _{\Delta x} \nabla V_{i}\left(x^{k}\right)^{T} \Delta x+\Delta x{ }^{T} H_{i}{ }^{k} \Delta x \\
\text { s.t. } \quad x^{k}+\Delta x
\end{gathered}
$$

Cut the step if necessary to obtain a new iterate $x^{k+1}=x^{k}+\alpha \Delta x$ with $\alpha \in(0,1)$. d. Go to step 2.a.

This problem has multiple local optima, as we observed when different initial values of the decision variables (four process variables) were given. We obtained the different sets of initial values using Latin Hypercube Hammersley Sampling. The best solution is selected as the one with the minimum BTEX emission at a given constraint of dry gas water content.

Figure 8 shows the flow diagram starting with the development of a metamodelbased optimization of the natural gas dehydration unit considering metamodel uncertainty. The process has seven steps: finding the uncertain variables and their operating range; input dataset generation; process simulation for output data generation using ProMax ${ }^{\circledR}$; metamodel generation using SVR; error estimation and uncertainty quantification using $\mathrm{KDE}$; input space; and error sampling, error propagation, and stochastic optimization using BONUS. The metamodel for optimization thus developed using uncertainty quantification is used to generate the Pareto optimal points by the $\varepsilon$-constrained method. The results from the BONUS optimal points are compared with those from SVR-EACO to find the Value of Stochastic Solution (VSS). Because we assume the ProMax ${ }^{\circledR}$ simulation as the real plant data, the optimal points obtained from the two methods are evaluated using ProMax ${ }^{\circledR}$ simulation. 


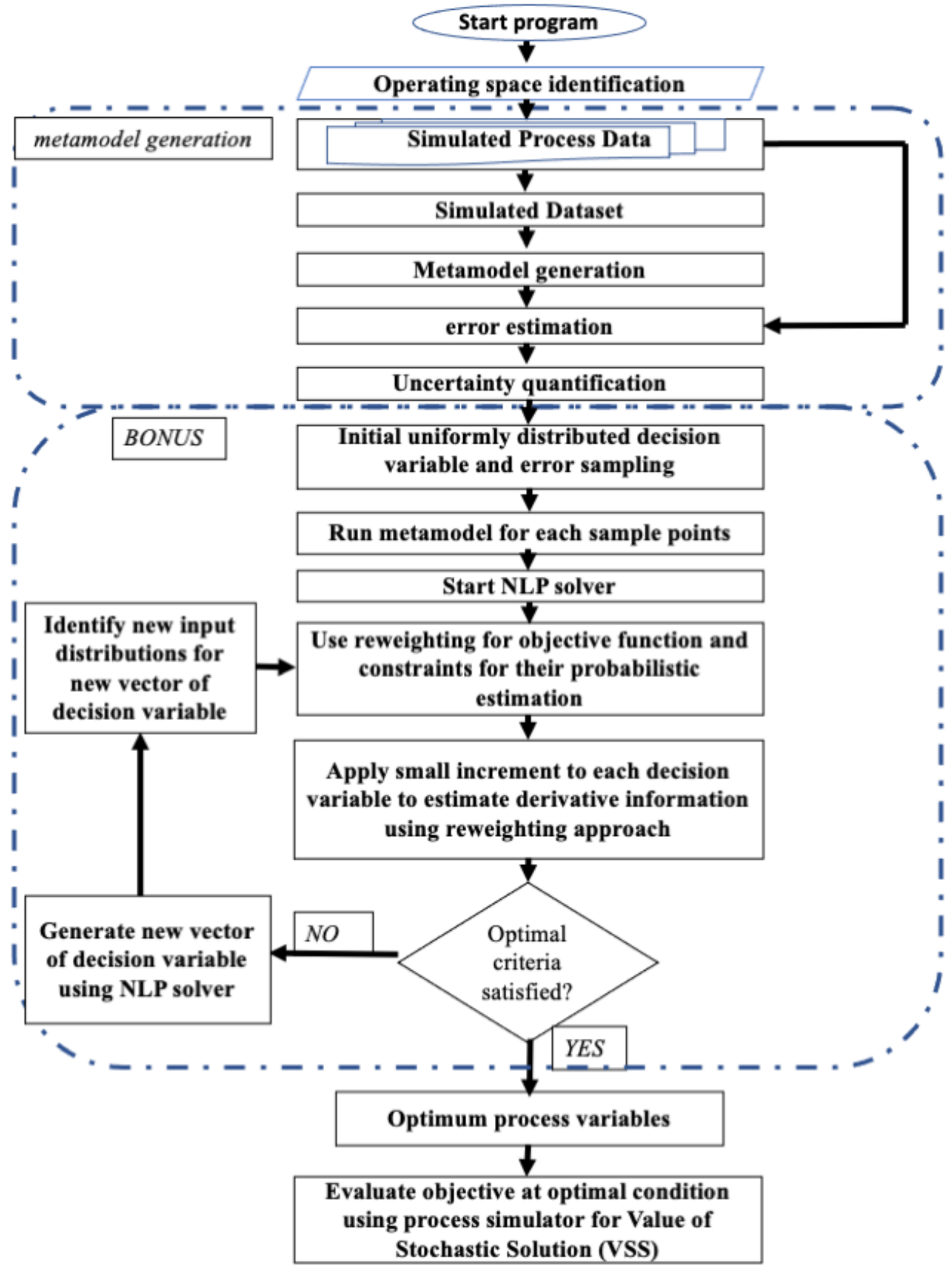

Figure 8. Algorithmic flowchart for metamodel-based optimization of the natural gas dehydration process with a BONUS reweighting scheme. 


\section{Results}

Five hundred scenarios were used for the metamodel generation. The data are provided in the supplementary material. Table 1 shows the two scenarios, from these 500 scenarios simulations, with the highest amount of dry gas water content and BTEX emission. The first scenario shows that BTEX emission can be as low as 65.58 ton/yr with the corresponding moisture content of dry gas of $13.89 \mathrm{lbm} / \mathrm{MMscf}$. This value of water content is higher than the maximum permissible limit of $7 \mathrm{lbm} / \mathrm{MMscf}$. The second scenario shows BTEX emission can be as high as 1238.21 ton/yr, and the corresponding moisture content is $2.41 \mathrm{lbm} / \mathrm{MMscf}$. The constrained optimization problem, as shown in Equations (3)-(5), (7), and (8), was solved. The SVR-based metamodels of the process were optimized using the BONUS algorithm. BONUS was performed for 32 optimal points by changing the constraint to obtain the Pareto set. Process simulation was conducted in ProMax ${ }^{\circledR}$; metamodel generation, error estimation, and uncertainty quantification were performed in MATLAB ${ }^{\circledR}$; and BONUS was conducted in an inhouse optimization module in FORTRAN, installed in a Windows ${ }^{\circledR}$ environment. In this process, we were able to compare SVR-BONUS-based metamodeling and optimization performance.

Table 1. The maximum and minimum value of BTEX and Dry Gas water content as obtained from process simulation [1].

\begin{tabular}{ccccccccc}
\hline No. & $\begin{array}{c}\text { Glycol } \\
\text { Circ. Rate } \\
\text { (sgpm) }\end{array}$ & $\begin{array}{c}\text { Absorber } \\
\text { Pressure } \\
\text { (psig) }\end{array}$ & $\begin{array}{c}\text { Inlet Glycol } \\
\text { Temp. } \\
\text { (Fahrenheit) }\end{array}$ & $\begin{array}{c}\text { Flash Gas } \\
\text { Pressure } \\
\text { (psig) }\end{array}$ & $\begin{array}{c}\text { Reboiler } \\
\text { Temp. } \\
\text { (Fahrenheit) }\end{array}$ & $\begin{array}{c}\text { Stripping } \\
\text { Gas Rate } \\
\text { (MSCFD) }\end{array}$ & $\begin{array}{c}\text { BTEX } \\
\text { Emission } \\
\text { (ton/yr) }\end{array}$ & $\begin{array}{c}\text { Dry Gas } \\
\text { Water } \\
\text { (LBM/MMscf) }\end{array}$ \\
\hline 1. & 1.01 & 563.80 & 124.69 & 51.93 & 389.11 & 5.96 & 65.58 & 13.89 \\
\hline 2. & 9.91 & 501.97 & 110.66 & 71.74 & 375.27 & 88.91 & 1238.21 & 2.41 \\
\hline
\end{tabular}

The base distribution consisting of the distribution of the decision and uncertain variables as used for optimization is shown in Table 2.

Table 2. Variables and their type of distributions as used in BONUS optimization.

\begin{tabular}{cccc}
\hline Variable Name & Variable Type & Distribution Type & Distribution Characteristics \\
\hline TEG Circulation Rate (GPM) & Decision variable & Uniform & 'lower', 1, 'upper', 10 \\
\hline Absorber Pressure (psig) & Decision variable & Uniform & 'lower', 500, 'upper', 600 \\
\hline $\begin{array}{c}\text { Reboiler Temp. (Fahrenheit) } \\
\text { Stripping Gas flow rate } \\
\text { (Mscfd) }\end{array}$ & Decision variable & Uniform & 'lower', 360, 'upper', 400 \\
\hline $\operatorname{err}_{\text {BTEX }(\%)}$ Decision variable & Uniform & Now', 0.0, 'upper', 100 \\
\hline $\operatorname{err}_{\operatorname{DryG}}(\%)$ & Uncertain variable & Standard deviation, 13.33 \\
\hline
\end{tabular}

\subsection{Pareto Front Generation}

Dehydration of natural gas is undertaken to prevent hydrate formation and/or liquid water deposition in the pipelines and to avoid condensation in the compressors. Thus, both the environmental objective of BTEX minimization and the reduction in the moisture content as an economic objective must be considered. Using the $\varepsilon$-constrained method, Pareto optimal points were generated to compare BTEX emissions with dry gas water content. Results from the optimization are shown in Table 3. 
Table 3. Optimized process conditions for the 32 Pareto points.

\begin{tabular}{|c|c|c|c|c|c|c|}
\hline \multirow{2}{*}{$\begin{array}{l}\text { Pareto } \\
\text { Points }\end{array}$} & \multicolumn{4}{|c|}{ Process Variables } & \multicolumn{2}{|c|}{$\begin{array}{l}\text { Results from ProMax } \\
\text { Process Simulation }\end{array}$} \\
\hline & $\begin{array}{l}\text { Glycol } \\
\text { Circ. Rate }\end{array}$ & $\begin{array}{l}\text { Absorber } \\
\text { Pressure }\end{array}$ & $\begin{array}{l}\text { Reboiler } \\
\text { Temp. }\end{array}$ & $\begin{array}{l}\text { Stripping } \\
\text { Gas Rate }\end{array}$ & $\begin{array}{c}\text { BTEX } \\
\text { Emission }\end{array}$ & $\begin{array}{c}\text { Dry Gas } \\
\text { Water }\end{array}$ \\
\hline & sgpm & psig & Fahrenheit & MSCFD & ton/yr & $\mathrm{lbm} / \mathrm{MMscf}$ \\
\hline A & 9.90 & 490.00 & 390.00 & 99.90 & 1323.29 & 0.81 \\
\hline B & 9.90 & 501.15 & 389.51 & 94.96 & 1295.49 & 0.83 \\
\hline $\mathrm{C}$ & 9.66 & 497.25 & 389.63 & 97.32 & 1281.33 & 0.85 \\
\hline $\mathrm{D}$ & 8.57 & 508.35 & 390.00 & 95.33 & 1142.04 & 1.04 \\
\hline $\mathrm{E}$ & 8.05 & 498.25 & 390.00 & 99.90 & 1108.06 & 1.12 \\
\hline $\mathrm{F}$ & 7.54 & 538.95 & 388.69 & 99.90 & 965.61 & 1.32 \\
\hline G & 5.55 & 546.25 & 357.41 & 13.52 & 670.15 & 3.42 \\
\hline $\mathrm{H}$ & 4.55 & 590.00 & 390.00 & 99.90 & 536.38 & 2.96 \\
\hline I & 3.84 & 511.88 & 373.70 & 9.68 & 486.35 & 4.34 \\
\hline $\mathrm{J}$ & 3.63 & 514.80 & 376.40 & 94.14 & 496.59 & 3.52 \\
\hline K & 3.55 & 584.47 & 390.00 & 82.64 & 411.16 & 4.06 \\
\hline $\mathrm{L}$ & 3.49 & 574.38 & 360.38 & 82.65 & 412.41 & 4.15 \\
\hline M & 2.98 & 586.50 & 369.32 & 57.66 & 327.27 & 5.13 \\
\hline $\mathrm{N}$ & 2.97 & 583.00 & 382.71 & 76.38 & 336.41 & 5.02 \\
\hline $\mathrm{O}$ & 2.96 & 599.94 & 399.94 & 100.00 & 333.05 & 5.14 \\
\hline $\mathrm{P}$ & 2.88 & 526.46 & 362.73 & 81.72 & 367.53 & 4.81 \\
\hline Q & 2.52 & 524.47 & 381.06 & 60.71 & 307.26 & 5.55 \\
\hline $\mathrm{R}$ & 2.32 & 532.91 & 390.00 & 99.78 & 290.02 & 6.05 \\
\hline$S$ & 2.21 & 515.33 & 372.52 & 28.71 & 251.86 & 6.53 \\
\hline $\mathrm{T}$ & 2.14 & 499.53 & 390.00 & 99.79 & 281.15 & 6.28 \\
\hline $\mathrm{U}$ & 2.03 & 599.69 & 376.68 & 42.04 & 195.22 & 7.83 \\
\hline $\mathrm{V}$ & 2.00 & 551.36 & 376.65 & 81.87 & 228.04 & 7.26 \\
\hline W & 2.00 & 587.63 & 383.45 & 83.62 & 214.04 & 7.66 \\
\hline$X$ & 2.00 & 570.06 & 359.51 & 99.41 & 227.40 & 7.47 \\
\hline $\mathrm{Y}$ & 2.00 & 582.63 & 389.99 & 95.70 & 221.00 & 7.59 \\
\hline $\mathrm{Z}$ & 2.00 & 580.67 & 390.00 & 99.27 & 223.24 & 7.57 \\
\hline AA & 2.00 & 556.57 & 375.30 & 62.37 & 217.58 & 7.36 \\
\hline $\mathrm{AB}$ & 2.00 & 544.40 & 354.41 & 14.54 & 199.01 & 7.96 \\
\hline $\mathrm{AC}$ & 2.00 & 590.00 & 375.41 & 46.71 & 197.37 & 7.80 \\
\hline $\mathrm{AD}$ & 1.79 & 600.00 & 376.34 & 37.69 & 164.76 & 8.82 \\
\hline $\mathrm{AE}$ & 1.72 & 594.24 & 374.39 & 31.88 & 155.32 & 9.13 \\
\hline $\mathrm{AF}$ & 1.31 & 545.47 & 394.27 & 80.35 & 139.12 & 10.46 \\
\hline
\end{tabular}

Pareto point A was obtained by minimizing BTEX emission for maximum dryness, i.e., minimum moisture content. Pareto points B to AF were obtained from BTEX emission minimization while relaxing the constraint for dry gas water content from the minimum value as obtained at Pareto point $\mathrm{A}$. The constraint in dry gas water content was increased in steps up to $10 \mathrm{lbm} / \mathrm{MMscf}$. The optimized process conditions from A to AF listed in Table 3 were also simulated in ProMax ${ }^{\circledR}$ process simulator. The results from the ProMax ${ }^{\circledR}$ 
process simulation at the optimal operating conditions are also shown in Table 3. Figure 9 shows the Pareto front generated with the process simulation and BONUS at the optimal points. Natural gas must be dried to ensure a moisture content as high as seven pounds of water per million standard cubic feet (LBM/MMscf) [37]. Suitable operating conditions as obtained from the BONUS-based optimization, as shown in Table 3, are between I and T. The optimal solution can be obtained at Q where both BTEX emission (307.26 ton/yr) and dry gas water content (5.55 lbm/MMscf) are minimized.

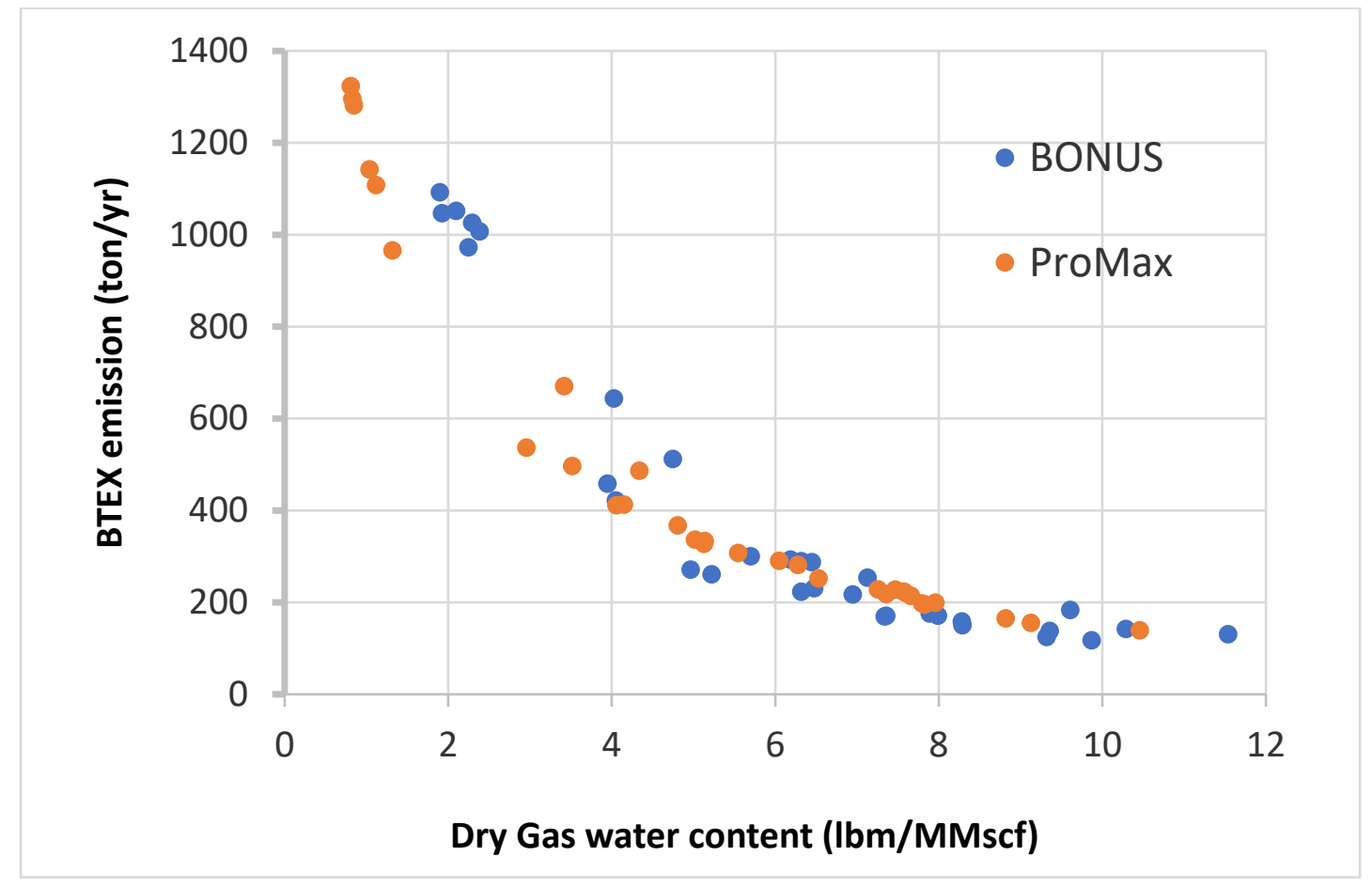

Figure 9. Pareto optimal points are predicted by SVR-BONUS optimization. Objective values at the optimal process conditions are obtained from BONUS and ProMax ${ }^{\circledR}$ process simulation.

\subsection{Value of Stochastic Solution (VSS)}

In our previous work, we used the efficient ant colony optimization (EACO) algorithm for an SVR-EACO optimization of natural gas processing units [1]. In EACO-based optimization, the error associated with the SVR model is not considered. The average value of the uncertain variables BTEX emission and dry gas water content as obtained from the SVR model is used for optimization. In the present work, we used probabilistic information of the uncertain variables to measure the Value of the Stochastic Solution (VSS). The difference between taking the average value of the uncertain variable for optimization as used in SVR-EACO when compared with stochastic analysis, i.e., propagating the uncertainties through the model as used in SVR-BONUS, is defined as the Value of the Stochastic Solution, VSS. The Pareto optimal points as predicted by SVR-BONUS and SVREACO optimization are shown in Figure 10. Values at the optimal process conditions are obtained from ProMax ${ }^{\circledR}$ process simulation at the optimal conditions as predicted by the two methods. To estimate the VSS, we compared the objective BTEX emission at different dry gas water content values as obtained from optimal process conditions suggested by SVR-EACO, with that from SVR-BONUS optimization using ProMax ${ }^{\circledR}$ process simulation at those optimal process conditions. 


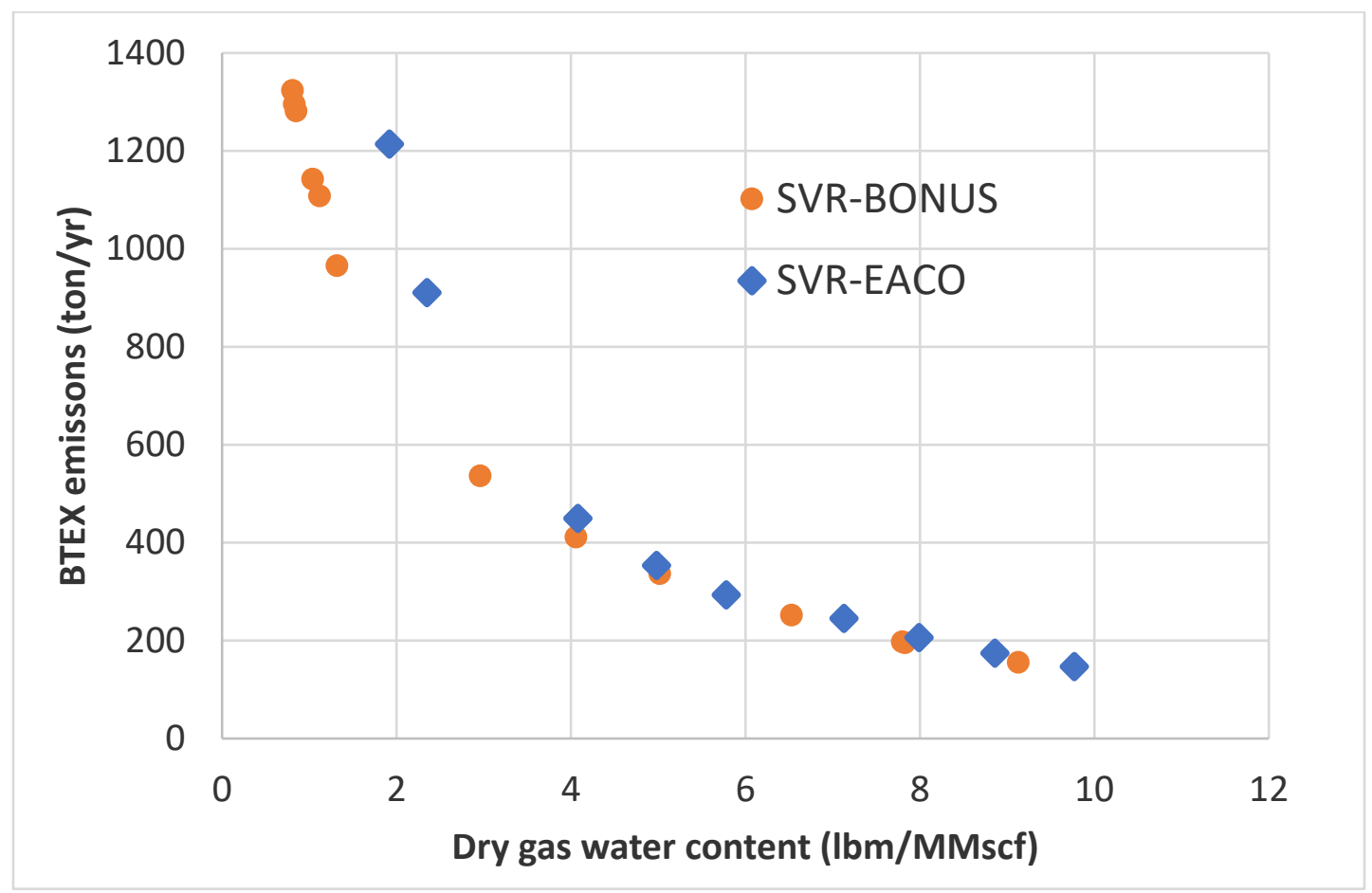

Figure 10. Pareto optimal points as predicted by SVR-BONUS and SVR-EACO optimization. Values at the optimal process conditions are obtained from ProMax ${ }^{\circledR}$ process simulation.

To compare the emission at a given dry gas water level from SVR-EACO and SVRBONUS optimization, extrapolation was undertaken of the results as obtained from SVRBONUS. The VSS for this problem is shown in Figure 11. The results reflect emission savings up to 405.25 tons per year.

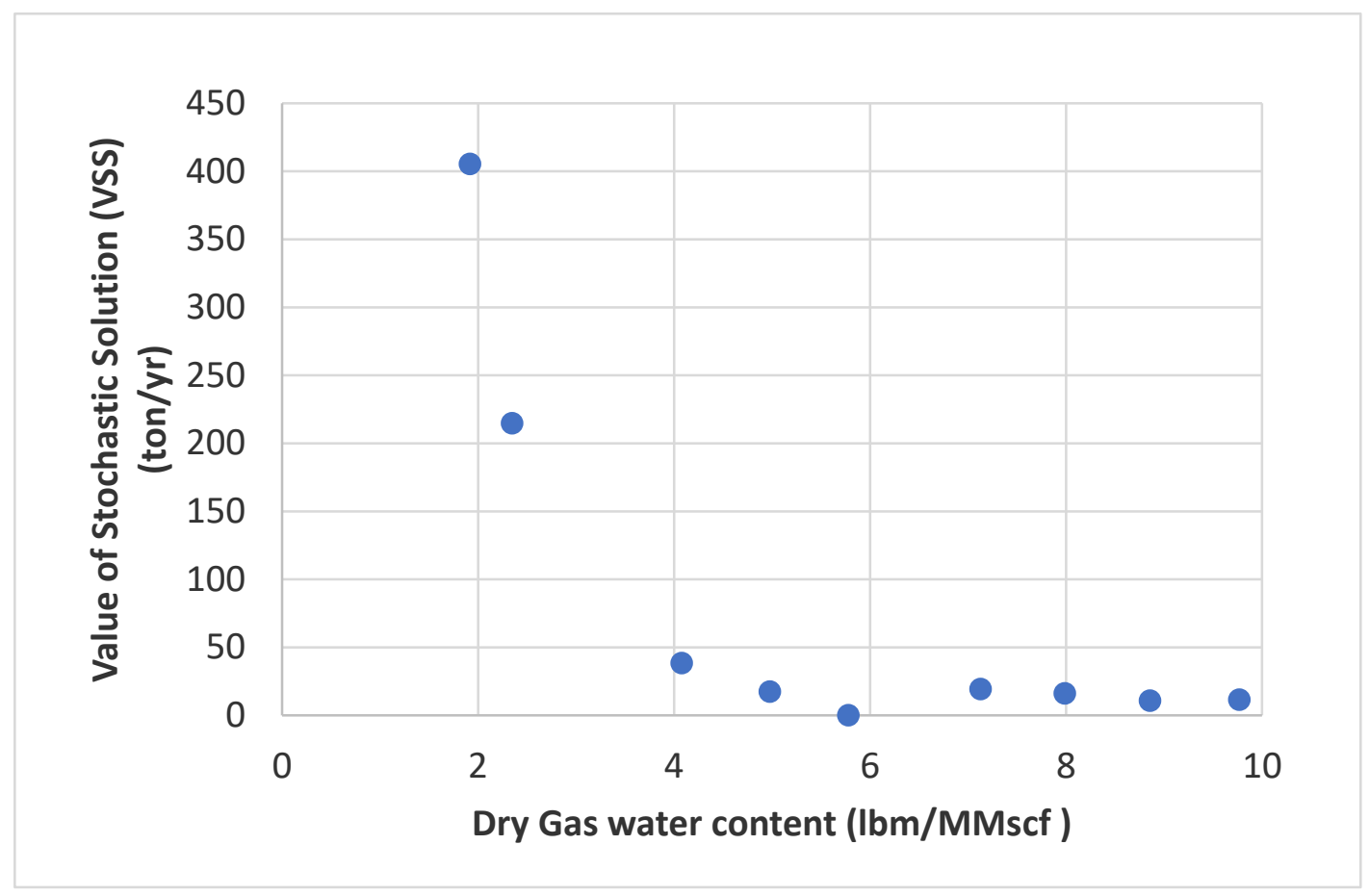

Figure 11. Value of Stochastic Solution (VSS) as obtained from the difference of deterministic optimization solution and stochastic optimization solution. 


\section{Discussion}

From the Pareto front, as shown in Figures 9 and 10, it can be found that the dry gas moisture content decreases at the cost of increased BTEX emission. From the 500 simulated scenarios, BTEX emission was found to be as high as 1238.21 ton/yr, and that of dry gas water content was $13.89 \mathrm{lbm} / \mathrm{MMscf}$, shown in Table 1. Comparing the maximum values with that from the Pareto optimal point $Q$ reveals that optimal operating conditions reduced the BTEX emission and dry gas water content by $75.19 \%$ and $60.04 \%$, respectively, from the highest possible value.

Break et al. [27] considered glycol circulation rate, stripping gas flow rate, flash tank pressure, and reboiler temperature to optimize the dehydration process. Simulating the present process with 100 MMSCFD at the optimal conditions found by Break et al. [27] resulted in an emission of $585.06 \mathrm{ton} / \mathrm{yr}$ and a dry gas water content of $3.89 \mathrm{lbm} / \mathrm{MMscf}$. Compared to the optimal solution obtained at Pareto point $Q$, we find BTEX emission as low as $307.26 \mathrm{ton} / \mathrm{yr}$, resulting in a significant reduction in emission, by $47.5 \%$, while keeping the dry gas water content within the permissible limit. Because BTEX emission depends on the process throughput and natural gas composition, it is imperative to obtain the optimal values of the process variables that mitigate emission.

The Pareto points from I to T, as shown in Table 3 are found to be in accordance with dry gas water content limits between 4 to $7 \mathrm{lbm} / \mathrm{MMscf}$, as recommended, while keeping a moderate BTEX emission. Through the process of stochastic optimization, we obtained the range of process variables at which Pareto optimal solutions for BTEX emission mitigation are feasible. BONUS optimizes by propagating the uncertainty through the model, and identified optimal process conditions that mitigate BTEX emission up to $405.25 \mathrm{ton} / \mathrm{yr}$ compared to that from deterministic optimization.

\section{Conclusions}

A hybrid algorithm was applied in this work that incorporates support vector regression with the BONUS algorithm for the modeling and optimization of the TEG dehydration process. Support vector regression is a machine learning technique for nonlinear regression. Using SVR, two different process models were developed. One correlates process variables with BTEX emission, and the other correlates dry gas water content with the same. We quantified modeling uncertainties due to machine learning and carried out the multi-objective stochastic optimization problem using BONUS, so that the BTEX emission was minimized with a constraint on the maximum water content in the processed gas. The $\varepsilon$-constraint method is used to obtain a Pareto optimal solution. The algorithm that involves SVR and BONUS is a novel method used for process optimization that considers uncertainty associated with the metamodel. The superior performance of the BONUS algorithm at low water content limits is attributed to the metamodel generated using limited data with low dry gas water content for the SVR model development, and the general model uncertainties associated with the machine learning model. To the best of our knowledge, this is the first time machine learning model uncertainties have been included in optimization to determine realistic Pareto solutions to a problem.

Supplementary Materials: The following are available online at https://www.mdpi.com/article/10 .3390 /en14196177/s1, Table S1: ProMax®simulated and Machine learning model generated BTEX emission and dry gas water content data at random realizations of the natural gas dehydration processing unit.

Author Contributions: Conceptualization, R.M. and U.M.D.; methodology, R.M. and U.M.D.; software, R.M. and U.M.D.; validation, R.M. and U.M.D.; formal analysis, U.M.D.; investigation, R.M. and U.M.D.; resources, R.M. and U.M.D.; data curation, R.M.; writing-original draft preparation, R.M.; writing-review and editing, U.M.D.; visualization, R.M. and U.M.D.; supervision, U.M.D.; funding acquisition, R.M. All authors have read and agreed to the published version of the manuscript.

Funding: This research was supported by the UT System's Rising STARs Grant Program, (grant number P5011032 34) awarded to RM. 
Institutional Review Board Statement: Not applicable.

Informed Consent Statement: Not applicable.

Data Availability Statement: Data are provided in the Supplementary Material.

Acknowledgments: The authors would like to acknowledge the support of Justin C. Slagle of Bryan Research \& Engineering (BRE).

Conflicts of Interest: The authors declare no conflict of interest. The funders had no role in the design of the study; in the collection, analyses, or interpretation of data; in the writing of the manuscript, or in the decision to publish the results.

\section{References}

1. Mukherjee, R.; Diwekar, U.M. Multi-objective optimization of the TEG dehydration process for BTEX emission mitigation using machine-learning and metaheuristic algorithms. ACS Sustain. Chem. Eng. 2021, 9, 1213-1228. [CrossRef]

2. Mukherjee, R.; El-Halwagi, M.M. Reliability of CHO symbiosis networks under source streams uncertainty. Smart Sustain. Manuf. Syst. 2018, 2, 132-153. [CrossRef]

3. Sahin, K.H.; Diwekar, U.M. Better Optimization of Nonlinear Uncertain Systems (BONUS): A new algorithm for stochastic programming using reweighting through Kernel density estimation. Ann. Oper Res. 2004, 132, 47-68. [CrossRef]

4. Diwekar, U.; David, A. BONUS Algorithm for Large Scale Stochastic Nonlinear Programming Problems; Springer: Berlin/Heidelberg, Germany, 2015.

5. Wilbur, S.; Bosch, S. Interaction Profile for: Benzene, Toluene, Ethylbenzene, and Xylenes (BTEX); Agency for Toxic Substances \& Disease Registry (ATSDR): 2004. Available online: https:/ / www.atsdr.cdc.gov/interactionprofiles/ip05.html (accessed on 26 September 2021).

6. Waxman, H.A. An Overview of the Clean Air Act Amendments of 1990. Envtl. L. 1991, 21, 1721.

7. Rueter, C.O.; Reif, D.L.; Menzies, W.R.; Evans, J.M. Measurement and enhanced monitoring of BTEX and VOC emissions from glycol dehydrators. SPE Adv. Technol. Ser. 1996, 4, 13-22. [CrossRef]

8. Gupta, A.; Ansari, N.A.K.R.; Rai, R.; Sah, A.K. Reduction Of Glycol Loss From Gas Dehydration Unit At Offshore Platform in Bombay Offshore-A Case Study. In Proceedings of the Abu Dhabi International Petroleum Exhibition and Conference, Society of Petroleum Engineers, Abu Dhabi, United Arab Emirates, 13 October 1996. [CrossRef]

9. Gandhidasan, P. Parametric analysis of natural gas dehydration by a triethylene glycol solution. Energy Sources 2003, 25, 189-201 [CrossRef]

10. Rahimpour, M.R.; Saidi, M.; Seifi, M. Improvement of natural gas dehydration performance by optimization of operating conditions: A case study in Sarkhun gas processing plant. J. Nat. Gas Sci. Eng. 2013, 15, 118-126. [CrossRef]

11. Jacob, N.C.G. Optimization of Triethylene Glycol (Teg) Dehydration in a natural gas processing plant. Int. J. Res. Eng. Res. Eng. Technol. 2014, 3, 346-350. [CrossRef]

12. Ranjbar, H.; Ahmadi, H.; Sheshdeh, R.K.; Ranjbar, H. Application of relative sensitivity function in parametric optimization of a tri-ethylene glycol dehydration plant. J. Nat. Gas Sci. Eng. 2015, 25, 39-45. [CrossRef]

13. Kamin, Z.; Bono, A.; Leong, L.Y. Simulation and optimization of the utilization of triethylene glycol in a natural gas dehydration process. Chem. Prod. Process. Modeling 2017, 12. [CrossRef]

14. Neagu, M.; Corsaro, D.L. Technical and economic evaluations of the triethylene glycol regeneration processes in natural gas dehydration plants. J. Nat. Gas Sci. Eng. 2017, 37, 327-340. [CrossRef]

15. Chebbi, R.; Qasim, M.; Jabbar, N.A. Optimization of triethylene glycol dehydration of natural gas. Energy Rep. $2019,5,723-732$. [CrossRef]

16. Mukherjee, R.; Sengupta, D.; Sikdar, S.K. Sustainability in the Context of Process Engineering, Clean Technol. Environ. Policy 2015, 17, 833-840. [CrossRef]

17. Sikdar, S.K.; Sengupta, D.; Mukherjee, R. Measuring Progress Towards Sustainability; Springer International Publishing: Cham, Switzerland, 2017. [CrossRef]

18. Mukherjee, R.; Reddy Asani, R.; Bopanna, N.; El-Halwagi, M.M. Optimal Design of Shale Gas Processing and NGL Recovery Plant under Uncertainty of the Feed Composition. J. Nat. Gas Sci. Eng. 2020, 83, 103517. [CrossRef]

19. Asani, R.R.; Mukherjee, R.; El-Halwagi, M.M. Optimal Selection of Shale Gas Processing and NGL Recovery Plant from Multiperiod Simulation. Process. Integr. Optim. Sustain. 2021, 5, 123-138. [CrossRef]

20. Li, W.; Gao, L.; Garg, A.; Xiao, M. Multidisciplinary robust design optimization considering parameter and metamodeling uncertainties. Eng. Comput. 2020, 1-18. [CrossRef]

21. Mukherjee, R.; Sengupta, D.; Sikdar, S.K. Parsimonious Use of Indicators for Evaluating Sustainability Systems with Multivariate Statistical Analysis. Clean Technol. Environ. Policy 2013, 15, 699-706. [CrossRef]

22. Mukherjee, R. Selection of Sustainable Process and Essential Indicators for Decision Making using Machine Learning Algorithms, Process. Integr. Optim. Sustain. 2017, 1, 153-163. [CrossRef]

23. Li, R.; Henson, M.A.; Kurtz, M.J. Selection of model parameters for off-line parameter estimation. IEEE Trans. Control Syst. Technol. 2004, 12, 402-412. [CrossRef] 
24. Mukherjee, R.; Diwekar, U.M.; Vaseashta, A. Optimal sensor placement with mitigation strategy for water network systems under uncertainty. Comput. Chem. Eng. 2017, 103, 91-102. [CrossRef]

25. Diwekar, U.; Mukherjee, R. Optimizing spatiotemporal sensors placement for nutrient monitoring: A stochastic optimization framework. Clean Technol. Environ. Policy 2017, 19, 2305-2316. [CrossRef]

26. Mukherjee, R.; Diwekar, U.M.; Kumar, N. Real-time optimal spatiotemporal sensor placement for monitoring air pollutants. Clean Technol. Environ. Policy 2020, 22, 2091-2105. [CrossRef]

27. Break, A.M.; Almehaideb, R.A.; Darwish, N.; Hughes, R. Optimization of process parameters for glycol unit to mitigate the emission of BTEX/VOCs. Process. Saf. Environ. Prot. 2001, 79, 218-232. [CrossRef]

28. Mukherjee, R.; Diwekar, U.M. Comparison of Monte Carlo and quasi-Monte Carlo technique in Structure and Relaxing Dynamics of Polymer in Dilute Solution. Comput. Chem. Eng. 2016, 84, 28-35. [CrossRef]

29. Wang, X.; Hickernell, F.J. Randomized Halton sequences. Math. Comput. Model. 2000, 32, 887-899. [CrossRef]

30. Ibrahim, M.; Al-Sobhi, S.A.; Mukherjee, R.; AlNouss, A. Influence of Sampling Technique on the Performance of Surrogate Model using ANN: A Case Study of Natural Gas Stabilization Unit. Energies 2019, 12, 1906. [CrossRef]

31. Mokhatab, S.; Poe, W.A.; Mak, J.Y. Chapter 7-Natural Gas Dehydration in Handbook of Natural Gas Transmission and Processing: Principles and Practices, 3rd ed.; Gulf Professional Publishing: Oxford, UK, 2015.

32. ProMax Foundations; Bryan Research \& Engineering, Inc.: 2015. Available online: http://www.bre.com/PDF/FoundationsManual-En.pdf. (accessed on 26 September 2021).

33. Diwekar, U. Introduction to Applied Optimization; Springer Science \& Business Media: Berlin/Heidelberg, Germany, 2008; Volume 22. [CrossRef]

34. Nandi, S.; Badhe, Y.; Lonari, J.; Sridevi, U.; Rao, B.S.; Tambe, S.S.; Kulkarni, B.D. Hybrid process modeling and optimization strategies integrating neural networks/support vector regression and genetic algorithms: Study of benzene isopropylation on Hbeta catalyst. Chem. Eng. J. 2004, 97, 115-129. [CrossRef]

35. Vapnik, V. The Nature of Statistical Learning Theory, 2nd ed.; Springer: New York, NY, USA, 1999. [CrossRef]

36. Vapnik, V.; Golowich, S.; Smola, A. Support vector method for function approximation, regression estimation and signal processing. Adv. Neural Inform. Process. Syst. 1996, 9, 281-287.

37. Phymetrix. Available online: http://www.phymetrix.com/industries-applications/natural-gas/ (accessed on 9 September 2021). 